\title{
Planting Design Approach in Sustainable Urban Planning
}

\author{
Demet Ulku Gulpinar Sekban \\ Department of Landscape Architecture, Karadeniz Technical University, Trabzon, Turkey \\ Ertan Düzgüneş \\ Department of Landscape Architecture, Karadeniz Technical University, Trabzon, Turkey
}

\begin{abstract}
The increased pressures associated with climate change and urbanization processes adversely affect the quality of life of the cities and damage the sustainability of the cities. Sustainability of a city depends on the social, economic and ecological flexible uses that these pressures can tolerate. The examination of these flexible uses within the city brings along the sustainability of the landscape. Landscape serving flexible uses for urban sustainability; All the unconscious elements that make up that landscape, especially the vegetation landscape element, should support the concept of sustainability. Within the scope of the study, it was aimed to determine sustainable design approaches in the fields of planting and to create an evaluation scale accordingly by examining the sustainable planting design approaches in urban scale. An answer was sought to the question of how sustainable the planting activities of Trabzon province are. In the study, 40 studies defined as sustainable landscape areas were examined and 27 sub-parameters were developed under 4 main titles within the framework of these studies. The parameters are examined in the regions represented by the city components that make up the city and it is tried to determine what is necessary for the sustainability of the city.
\end{abstract}

\author{
Article History \\ Received: 27 July 2020 \\ Received in revised form: 01 january 2021 \\ Accepted: 18 February 2021 \\ Published Online: 30 April 2021
}

Keywords:

Sustainable planting design, sustainable planting, sustainable cities, urban planning, Trabzon

Corresponding Author Contact:

demetsekban@ktu.edu.tr

DOI: $10.11113 /$ ijbes.v8.n2.674

\section{Introduction}

The pace of consumption and disruption of natural resources of humankind as the result of population increase, has now outdone the regeneration speed of the nature (Alberti, 2005). The fact that the nature could not recover the damages it suffered brought about many interrelated problems, and their impacts have become more visible in recent years. Rapid population growth and urbanization, technological developments, industrialization, nonenvironmentally friendly manufacturing and consumption patterns, as well as faulty policies adopted, are among the main factors causing these sorts of problems.

Disruption on a global or regional scale brought about by deteriorating natural environment as the result of human-oriented utilizations has played an important role in generation of the concept of "sustainability". Sustainability, which is defined as maintaining intactness and continuity of resource values by not exceeding carrying capacity, is a multidisciplinary term (Aklanoğ lu, 2009; Bozdoğ an, 2003; Collins, 1999; Çakılcıog lu, 2002). Foundations of the term sustainability were first laid with the Stockholm Declaration adopted by the UN Conference on the Human Environment held in Stockholm, Sweden in 1972. The Second Principle of the Declaration, signed by 113 countries including Turkey, stresses that the natural resources of the earth, including air, water, land, flora and fauna and especially representative samples of natural ecosystems, must be safeguarded for the benefit of present and future generations by means of careful planning (Stockholm Decleration, 1972). However, sustainability could not attain its current status until the 
Brundtland Report issued by World Commission on Environment and Development in 1987. It was stated in the $7^{\text {th }}$ chapter of the Report that sustainable development policies and programs should be adopted in order to ensure environmental sustainability and prevent the loss of biodiversity and environmental resources (WCED, 1987). Two separate protocols, namely for the 'developed' and 'developing' members, were prepared in the Kyoto Protocol signed in 1997, as the goals set in Rio Conference had not been attained, so that parties to the protocol could reduce their carbon emissions as low as the targeted limits, improve technologies to attain this goal and, in return, ensure sustainability of the resource values. In 2002, during the World Summit on Sustainable Development, which took place in Johannesburg (South Africa) in presence of the representatives of 191 countries, it was stressed that action schemes and strategies for sustainable development could be revised in the light of the goals determined. In the Rio+20 Summit held in Rio 2012, on the other hand, the concepts of 'sustainable development' and 'green economy' were discussed, and the consensus document called "The Future We Want" was signed by participating nations (SKD, 2016).

Urban settlements, which are the leading actors in disrupting natural ecosystems, hosted more than half of the total population of the world as of 2009 (Status of the World, 2016 ). Urban areas occupying only $2 \%$ of the surface area of the entire world are responsible for $80 \%$ of the carbon emission, $60 \%$ of water consumption and $80 \%$ of wood consumption (Grimm et al., 2008). In this respect, even if they have been the driving force of economic development, urbanized settlements of present day must be re-planned in the sense of sustainability to ensure the survival of natural cycles.

Sustainable cities are expected to consist of flexible systems and networks that have a balanced and harmonious ecosystem in social, economic and ecological terms (Alberti, 1996). Yet, it is not always easy to accomplish the multidimensional planning of such urban systems and networks (Braulio-Gonzalo, Bovea, \& Ruá, 2015). That is because cities are rather complex and rigid systems that are in constant interaction with one another in biological and physical terms (Pickett, McGrath, Cadenasso, \& Felson, 2014). Sustainable cities, therefore, should be the combination of flexible and living systems that focus on solving environmental problems, meeting ever-changing needs of society and that can resist internal and external threats. In this respect, extra attention should be paid to landscape design, and consequently, the effect of the landscape design on the balance of urban environment in the scope of sustainable urban areas (Coccolo, Kämpf, Mauree, \& Scartezzini, 2018).

\subsection{Relationship of Sustainable Urban Areas and Planting Design}

When the concept of sustainability is combined with landscape, sustainable landscapes are supposed to be environmentally conscious combinations of spaces and systems that play an active role in social life and meet social needs (Gould \& Lewis, 2017), because natural and artificial elements of a landscape area generate intra-urban and extra-urban comfort by providing environmental advantages through social interaction, thus increasing the quality of life (Xiao, Dong, Yan, Yang, \& Xiong, 2018). Provided we design landscape areas to attain comfort based on the concept of sustainability, can we create living spaces that tolerate the negative impacts of urban areas on the environment in a multidimensional way.

While landscape incorporates habitats supporting urban biodiversity thanks to its green spaces on the one hand, it cleans the urban air by storing the carbon in the air on the other. Aside from these, green spaces increase the quality of lives of urban people as they lessen the effects of heat islands (Atwa, Ibrahim, Saleh, \& Murata, 2019; Fitzgerald, 2010; Selman, 2008; Xiao et al., 2018).

In order to be able to benefit from the green spaces of the landscape and contribute to the sustainability of the urban areas, continuity of these spaces within the elements of the city should be taken into account. Designs whose continuity is maintained in the urban elements but their continuity is not ensured in the sense of sustainable designs may end up with spaces that requires excessive use of such resources as water, energy and maintenance. The more the need for resources, the heavier are the risks posed on the sustainability of a given green space. Unsustainable landscape designs turn out to be rather disadvantageous for the urban areas, and bring along environmental, social and economic problems.

So as to maintain sustainability of the landscape, designers must make sure that they use natural and economic resources efficiently and consider design in a multidimensional way (Nikologianni, Moore, \& Larkham, 2019). Sustainability in landscape design is a combination of concepts composed of numerous constituents and many 'rights'. The concept of sustainable landscape focuses on three fundamental subjects on the urban scale. First of them is design and protection of natural assets and resources; the second is emphasizing, protecting and utilizing the dynamics constituting ecosystems and multifunctional relationships, and the third is the welfare of inhabitants of the urban areas (Acar, Gülpınar Sekban, \& Acar, 2017; Gülpınar Sekban, Bekar, \& Acar, 2018; Selman, 2008). Accordingly, it is not always possible to say that every successful sustainable landscape design is suitable or right for any given place, because every urban area is a living metabolism, which has its own characteristics, shaped by its special dynamics, and seeks to meet the needs of only its residents (Maclaren, 1996). Authentic and contemporary approaches should be developed on how the space and landscape will work for any landscape to be designed to ensure that landscape design serves to the understanding of sustainable urbanization, and on how it will interact with the dynamics that constitute the ecosystem, both on local and global scale (Maclaren, 1996; Nikologianni et al., 2019). Such an approach accompanies a set of comprehensive and genuine parameters. American Society of Landscape Architects (ASLA) specified the main components of parameters required for sustainable landscape design as choice of land and placement, vegetation, water consumption, soil, air and energy, waste management and choice of materials, and defined different landscapes accordingly (ASLA, 2018). Defined landscapes can only contribute to the sustainability of the urban areas when all the elements constituting the landscape - especially vegetation elements of landscape- do support the concept of sustainability (Nikologianni et al., 2019). In order to achieve this, planting 
design, where vegetation elements of landscape are used, must to be planned and implemented in accordance with sustainable design criteria. Plants, the main element of planting design, are ever-changing, developing biological assets that have dynamic characteristics. Therefore, plants occupy an important place in people's lives both functionally and aesthetically. Beyond their importance for human life, plants are such landscape design elements that have aesthetic, economic and ecological functions on the urban scale. Plants help balancing the interaction among users, urban area and nature by adding both visual and functional values to the city. In this way, they ensure the sustainability of the ongoing relationship between the environmental systems and users in the equilibrium of preservation-utilization, which can only be achieved through accomplishing the sustainability of intraurban green spaces in structural and botanical terms.

In the current study, an answer was sought for the question: "What should planting design approaches be like in sustainable urban planning?" The main purpose of the study is to determine the sustainable planting parameters, for which a consensus has yet to appear in the literature, by assessing them as a whole and to create a rating scale accordingly. In the scope of the study, planting designs implemented within the elements of urban areas were scrutinized. Sustainability status of several already designed and implemented planting areas were discussed as per the generated rating scale. Defaults of parameters deemed necessary for the sustainability of urban planting were spotted. This study is expected to serve as a guide for designers to ensure the sustainability of urban planting schemes to be implemented in the future. In conclusion, deficiencies in sustainable planting designs implemented in the province of Trabzon were highlighted, and further steps were proposed to alleviate sustainability problems of the city.

\section{Material and Method}

The material of the current study is made up of urban areas located within the borders of downtown Trabzon and that represent specific elements determined according to the method (Figure 1). In the scope of the method, 40 individual studies conducted by American Society of Landscape Architects (ASLA)

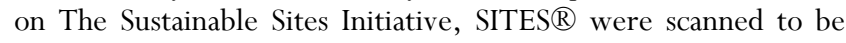
able to determine the sustainable planting parameters. Accordingly, 4 main and 27 sub-parameters were identified (Atwa et al., 2019; Braulio-Gonzalo et al., 2015).

Taking the five elements that make up the urban area (paths, edges, districts, nodes and landmarks) (Lynch, 2010) as a reference, sample areas that represent downtown Trabzon were specified, which are;
Paths: Yavuz Selim Boulevard (Tanjat Road), BeŞ irli Coastal Road, Atatürk Boulevard, Maras Avenue

Edges: Besirli Coast, Atatürk Boulevard, Degirmendere Streambed, Ganita Beach, Trabzon Port, MaraŞ Avenue

Districts: Besirli, Kalkınma, Kanuni Campus of Karadeniz Technical University, Çamlık, Ortahisar

Nodes: Meydan Park, Ayasofya Junction, Degirmendere Junction, İ tfaiye Junction

Landmarks: Ayasofya Museum, Boztepe Sightseeing Site, Trabzon Airport, Akyazı Stadium, Forum Shopping Center, Ganita

144 experts were administered the "Delphi Survey" (Hess \& King, 2002) to identify each and every element that best represents the area it is related to. Then, the same group of experts were asked to score the parameters specified for sustainable planting designs within certain groups of parameters in terms of importance, so as to determine the effect rate of each parameter.

To find the effect rates of the main parameters, initially, sustainability coefficients (SC) of each title were calculated. In order to do that, the sum of scores given by participants (SP) was divided by the number of participants (n).

$$
\mathrm{SC}_{\text {main group }}=\frac{\sum S P}{n}
$$

To find the effect rates of sub-parameters, on the other hand, the sum of scores given by participants (SPP) was divided by the number of participants (n), and as each main title does not contain equal number of sub-parameters, the attained result was divided by the number of sub-parameters $\left(n_{\mathrm{p}}\right)$ within each set.

$$
\mathrm{ERP}=\left[\frac{\sum S P P}{n}\right] / n_{\mathrm{p}}
$$

In this way, sustainable planting design was evaluated on the scale of downtown Trabzon, and the level of sustainability of the existing planting schemes in the Province of Trabzon was revealed. 
Urban Elements; Paths
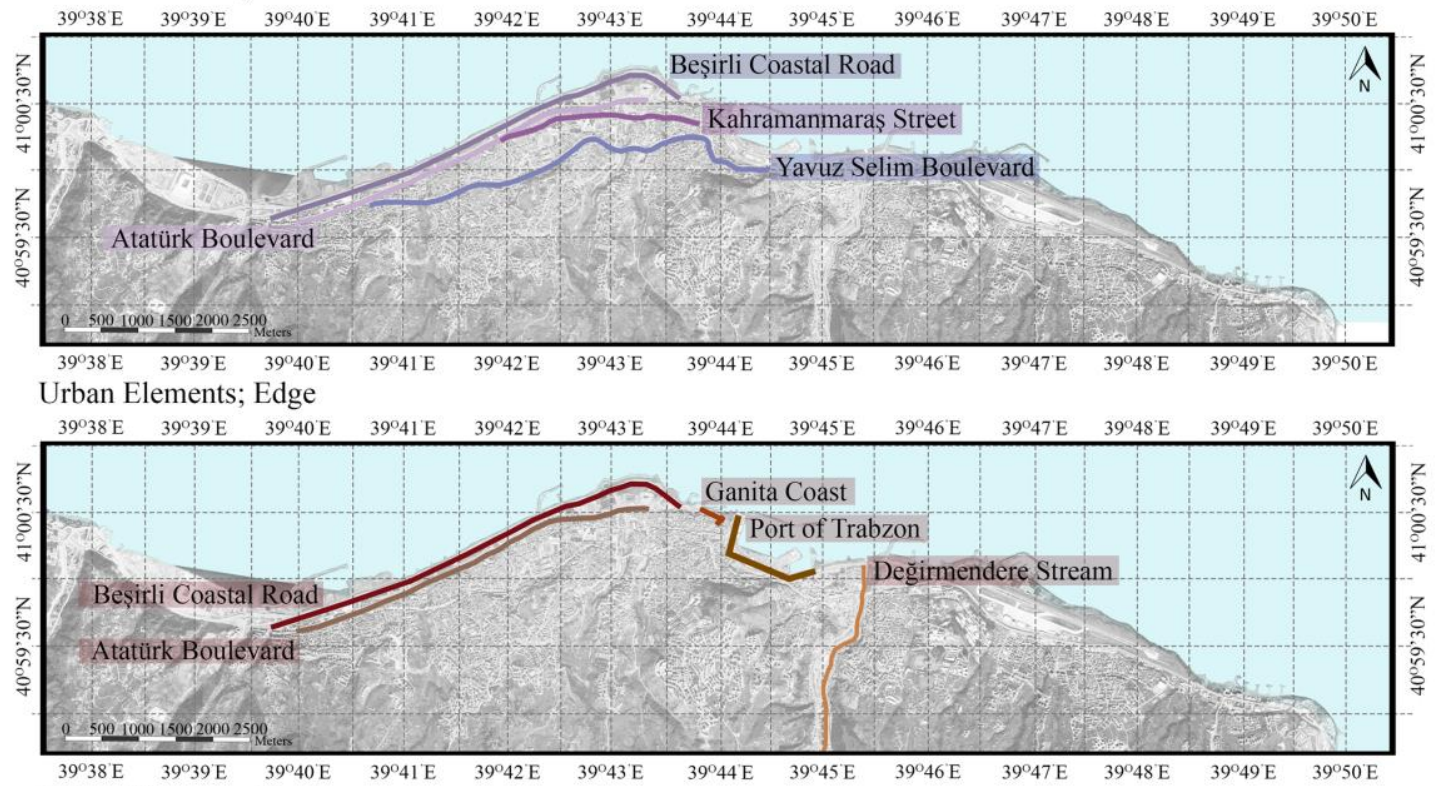

Urban Elements; Districts

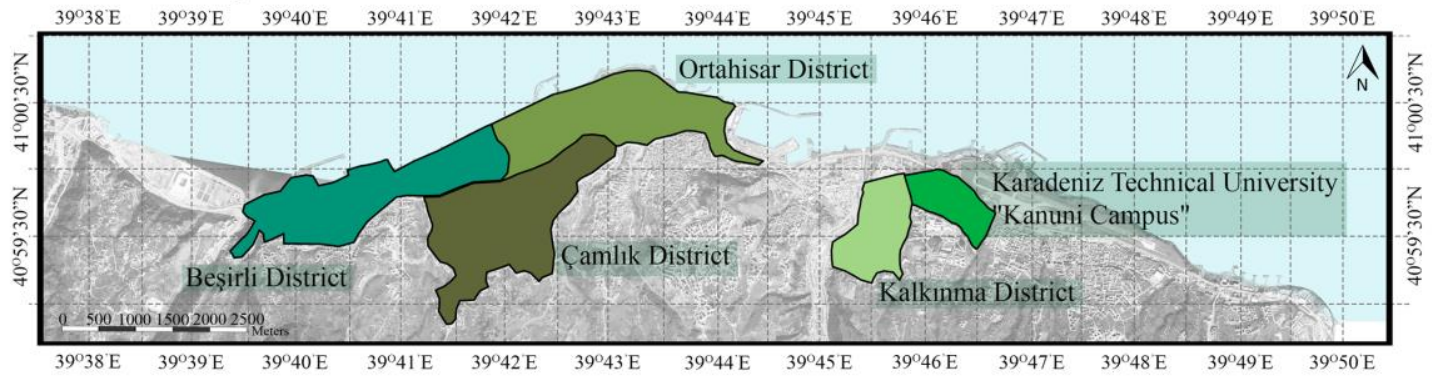

Urban Elements; Nodes

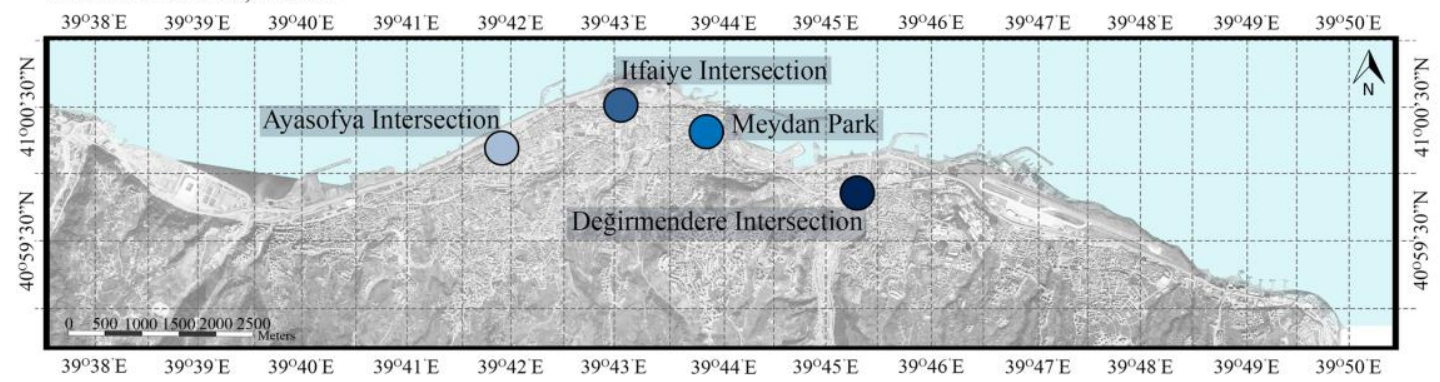

Urban Elements; Landmarks

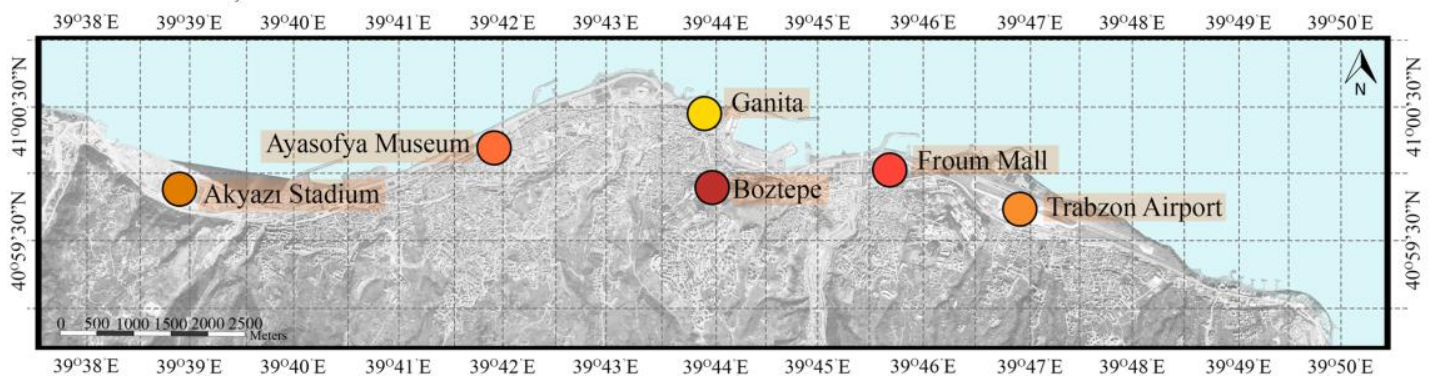

Figure 1 Locations of study areas according to urban elements

\section{Findings}

Main parameters and sub-parameters identified through literature review are presented in Table 1. The demographical structure of the participants and the distribution of percentages of preference of the specified areas as the result of the Delphi Survey administered to find the areas that best represent the five main urban elements are presented in Table 2. 
According to Table 2, 38.21\% of the participants specified Maraş Avenue as the path element, 29.89\% regarded Beş irli Coast as the edge element, $36.13 \%$ spotted Kanuni Campus of
Karadeniz Technical University as the district element, $61.12 \%$ saw Meydan Park as the node element, and 33.36\% chose Ayasofya Museum as the landmark element.

Table 1 Sustainable planting parameters on the urban scale

\begin{tabular}{|c|c|}
\hline Sustainable Planting Parameters & Parameter Codes \\
\hline \multicolumn{2}{|l|}{ Material } \\
\hline Use of natural elements in planting design and implementation & $\mathrm{M}_{1}$ \\
\hline Use of recycled elements in planting design and implementation & $\mathrm{M}_{2}$ \\
\hline Healthy specimens of plant species used in planting design and implementation & $\mathrm{M}$ \\
\hline Use of natural/endemic species in the area & $\mathrm{M}$ \\
\hline \multicolumn{2}{|l|}{ Ecology } \\
\hline Variety of plant species used in the project area & $\mathrm{E}_{1}$ \\
\hline Majority of species used in planting are natural & $\mathrm{E}_{2}$ \\
\hline Adaptability of the species used in the design to the climatic conditions & $\mathrm{E}_{3}$ \\
\hline Tolerance of the species used in the design to air pollution & $\mathrm{E}$ \\
\hline The plants used in the area support the variety of animals, meet their needs of feeding, sheltering and safety. & $\mathrm{E}_{5}$ \\
\hline Existence of a plan and a design for water management & $\mathrm{E}_{6}$ \\
\hline Existence of an arrangement that will make use of rain water and excess water & E- \\
\hline Use of species that are resistant to diseases & $\mathrm{E}_{\mathrm{s}}$ \\
\hline Taking and implementing decisions that are suitable for the soil characteristics & Es \\
\hline Inclination of the species used in the design to balance the urban ecosystem and create a micro-climate effect & $\mathrm{E}_{10}$ \\
\hline \multicolumn{2}{|l|}{ Management/Maintenance/Economy } \\
\hline The seed resource value of the plants used & $\mathrm{MME}_{1}$ \\
\hline Low maintenance need of the area & $\mathrm{MME}_{2}$ \\
\hline Spatial function of the plants used in design & MME \\
\hline Protection and maintenance plan for plant species with special status in the area & MME \\
\hline Management and maintenance program for the control of invasive species & MME \\
\hline Contribution of the area to the local economy & $\mathrm{MME}_{6}$ \\
\hline Existence of a soil management plan & MME \\
\hline Planning schemes supporting recycling (i.e. transforming the fallen leaves as compost) & $\mathrm{MME}_{\mathrm{S}}$ \\
\hline \multicolumn{2}{|l|}{ Planning/Design } \\
\hline Contribution of the design to the consciousness of sustainability & $\mathrm{PD}$ \\
\hline Suitability of species used in the area for all seasons & $\mathrm{PD}_{2}$ \\
\hline Compatibility of the design with the topography of the area; support of topography utilization & $\mathrm{PD}$ \\
\hline Use of species that have an important place in the culture and/or history of the area. & $\mathrm{PD}$ \\
\hline Taking into consideration the criteria of accessibility and guidance in selection of spots for plant species in the design & $\mathrm{PD}$ \\
\hline
\end{tabular}

Table 2 Demographical structure of the participants and preference of urban elements

\begin{tabular}{|c|c|c|c|}
\hline \multicolumn{4}{|c|}{ Demographical Structure of Participants } \\
\hline \multicolumn{4}{|c|}{ Gender } \\
\hline Female & 85 Participants & Male & 59 Participants \\
\hline \multicolumn{4}{|l|}{ Job } \\
\hline Landscape architect & 46 Participants & Forest engineer & 30 Participants \\
\hline Architect & 33 Participants & Others & 35 Participants \\
\hline \multicolumn{4}{|l|}{ Urban Elements } \\
\hline Path Element & Preference Per.(\%) & Path Element & Preference Per.(\%) \\
\hline Yavuz Selim Boulevard (Tanjat Road) & $16.66 \%$ & Atatürk Boulevard & $18.05 \%$ \\
\hline Beş irli Coastal Road & $27.08 \%$ & Maras Avenue & $38.21 \%$ \\
\hline Edge Element & Preference Per.(\%) & Edge Element & Preference Per.(\%) \\
\hline Besirli Coast & $29.89 \%$ & Degirmendere Streambed & $21.52 \%$ \\
\hline Atatürk Boulevard & $14.58 \%$ & MaraŞ Avenue & $7.63 \%$ \\
\hline Ganita Beach & $13.19 \%$ & Trabzon Port & $13.19 \%$ \\
\hline District Element & Preference Per.(\%) & District Element & Preference Per.(\%) \\
\hline Beş irli & $\% 22,22$ & $\begin{array}{l}\text { Kanuni Campus of Karadeniz } \\
\text { Technical University }\end{array}$ & $36.13 \%$ \\
\hline Kalkınma & $8.33 \%$ & Çamlık & $2.08 \%$ \\
\hline Ortahisar & $31.24 \%$ & & \\
\hline
\end{tabular}




\begin{tabular}{lclc}
\hline Node Element & Preference Per.(\%) & Node Element & Preference Per.(\%) \\
\hline Meydan Park & $61.12 \%$ & Ayasofya Junction & $27.08 \%$ \\
\hline$\dot{I}$ tfaiye Junction & $3.47 \%$ & Degirmendere Junction & $8.33 \%$ \\
\hline Landmark Element & Preference Per.(\%) & Landmark Element & Preference Per.(\%) \\
\hline Ayasofya Museum & $33.36 \%$ & Boztepe Sightseeing Site & $26.38 \%$ \\
\hline Akyazi Stadium & $6.25 \%$ & Trabzon Airport & $9.02 \%$ \\
\hline Forum Shopping Center & $14.58 \%$ & Ganita & $10.41 \%$ \\
\hline
\end{tabular}

According to Table 2, 38.21\% of the participants specified Maraș Avenue as the path element, 29.89\% regarded BeŞ irli Coast as the edge element, $36.13 \%$ spotted Kanuni Campus of Karadeniz Technical University as the district element, 61.12\% saw Meydan Park as the node element, and 33.36\% chose Ayasofya Museum as the landmark element.
Then, the coefficients of 4 main parameters and the effect rates of sustainable planting parameters were calculated within their sets. Accordingly, it was revealed that the main parameter "Ecology" had an effect on sustainability by 3.16, "Management/Maintenance/Economy" by 2.55, "Planning and Design" by 2.27 and "Material" by 2 (Table 3 ).

Table 3 Sustainability coefficients and effect rates of sustainable planting parameters

\begin{tabular}{|c|c|c|}
\hline \multicolumn{3}{|c|}{ Sustainability Coefficients (SC) } \\
\hline Parameter & Material & 2 \\
\hline \multicolumn{3}{|c|}{ Effectiveness Rates of Sustainable Planting Parameters (ERP) } \\
\hline $\mathrm{M}_{1}$ & Use of natural elements in planting design and implementation & 0,916667 \\
\hline $\mathrm{M}_{2}$ & Use of recycled elements in planting design and implementation & 0,652778 \\
\hline $\mathrm{M}_{3}$ & Healthy specimens of plant species used in planting design and implementation & 0,333333 \\
\hline $\mathrm{M}_{4}$ & Use of natural/endemic species in the area & 0,597222 \\
\hline \multicolumn{3}{|c|}{ Sustainability Coefficients (SC) } \\
\hline & Ecology & 3,16 \\
\hline \multicolumn{3}{|c|}{ Effectiveness Rates of Sustainable Planting Parameters (ERP) } \\
\hline $\mathrm{E}_{1}$ & Variety of plant species used in the project area & 0,427778 \\
\hline $\mathrm{E}_{2}$ & Majority of species used in planting are natural & 0,766667 \\
\hline $\mathrm{E}_{3}$ & Adaptability of the species used in the design to the climatic conditions & 0,672222 \\
\hline $\mathrm{E}_{4}$ & Tolerance of the species used in the design to air pollution & 0,538889 \\
\hline$E_{5}$ & $\begin{array}{l}\text { The plants used in the area support the variety of animals, meet their needs of feeding, sheltering and } \\
\text { safety }\end{array}$ & 0,527777 \\
\hline $\mathrm{E}_{6}$ & Existence of a plan and a design for water management & 0,594444 \\
\hline $\mathrm{E}_{7}$ & Existence of an arrangement that will make use of rain water and excess water & 0,605556 \\
\hline $\mathrm{E}_{8}$ & Use of species that are resistant to diseases & 0,311111 \\
\hline $\mathrm{E}_{9}$ & Taking and implementing decisions that are suitable for the soil characteristics & 0,483333 \\
\hline $\mathrm{E}_{10}$ & $\begin{array}{l}\text { Inclination of the species used in the design to balance the urban ecosystem and create a micro-climate } \\
\text { effect }\end{array}$ & 0,655556 \\
\hline \multicolumn{3}{|c|}{ Sustainability Coefficients (SC) } \\
\hline & Management/Maintenance/Economy & 2,55 \\
\hline \multicolumn{3}{|c|}{ Effectiveness Rates of Sustainable Planting Parameters (ERP) } \\
\hline $\mathrm{MME}_{1}$ & The seed resource value of the plants used & 0,680556 \\
\hline $\mathrm{MME}_{2}$ & Low maintenance need of the area & 0,805556 \\
\hline $\mathrm{MME}_{3}$ & Spatial function of the plants used in design & 0,479167 \\
\hline $\mathrm{MME}_{4}$ & Protection and maintenance plan for plant species with special status in the area & 0,493056 \\
\hline $\mathrm{MME}_{5}$ & Management and maintenance program for the control of invasive species & 0,486111 \\
\hline $\mathrm{MME}_{6}$ & Contribution of the area to the local economy & 0,416667 \\
\hline $\mathrm{MME}_{7}$ & Existence of a soil management plan & 0,5 \\
\hline $\mathrm{MME}_{8}$ & Planning schemes supporting recycling (i.e. transforming the fallen leaves as compost) & 0,722222 \\
\hline \multicolumn{3}{|c|}{ Sustainability Coefficients (SC) } \\
\hline & Planning/Design & 2,27 \\
\hline \multicolumn{3}{|c|}{ Effectiveness Rates of Sustainable Planting Parameters (ERP) } \\
\hline $\mathrm{PD}_{1}$ & Contribution of the design to the consciousness of sustainability & 0,733333 \\
\hline $\mathrm{PD}_{2}$ & Suitability of species used in the area for all seasons & 0,622222 \\
\hline $\mathrm{PD}_{3}$ & Compatibility of the design with the topography of the area; support of topography utilization & 0,644444 \\
\hline
\end{tabular}




\begin{tabular}{llr}
\hline $\mathrm{PD}_{4}$ & Use of species that have an important place in the culture and/or history of the area. & 0,488889 \\
\hline $\mathrm{PD}_{5}$ & $\begin{array}{l}\text { Taking into consideration the criteria of accessibility and guidance in selection of spots for plant } \\
\text { species in the design }\end{array}$ & 0,511111 \\
\hline
\end{tabular}

Close examination of sub-parameters listed under 4 main parameters according to Table 3 revealed that the "Use of natural elements in planting design and implementation" sub parameter of the "material" parameter had the highest effect rate with a score of 0.916667 , while "Healthy specimens of plant species used in planting design and implementation" subparameter had the lowest effect rate with a score of 0.333333 .

10 sub-parameters were scrutinized under "ecology" main parameter. Findings revealed that "Majority of species used in planting are natural" sub-parameter had the highest effect rate with a score of 0.766667 , while "Use of species that are resistant to diseases" sub-parameter had the lowest effect rate with a score of 0.311111 .

Among the sub-parameters of "Management/Maintenance/Economy" main parameter, "Low maintenance need of the area" sub-parameter had the highest effect rate with a score of 0.805556 , while "Contribution of the area to the local economy" sub-parameter had the lowest effect rate with a score of 0.416667 .

5 sub-parameters were listed under "Planning/Design" main parameter. In this set, "Contribution of the design to the consciousness of sustainability" sub-parameter had the highest effect rate with a score of 0.733333 , while "Use of species that have an important place in the culture and/or history of the area" sub-parameter had the lowest effect rate with a score of 0.488889 .

When all 27 sub-parameters listed under 4 main parameters in the scope of sustainable planting design were considered, it was seen that the sub-parameter of "Majority of species used in planting are natural" had the highest effect rate among 27 subparameters when its mere score of 0.766667 was multiplied by the sustainability coefficient of the main parameter it is related to. Even if the "Healthy specimens of plant species used in planting design and implementation" sub-parameter had an effect rate of 0.333333 in its own set, it had the lowest effect rate among all the sub-parameters with a score of 0.666667 when it was multiplied by the relevant sustainability coefficient.

\subsection{Evaluation of Downtown Trabzon in Accordance with Sustainable Planting Parameters}

The areas Maraş Avenue, Beş irli Coastal Road, Kanuni Campus of Karadeniz Technical University, Meydan Park and Ayasofya Museum, which constitute the elements of the urban area and which were chosen as the representatives of the elements, were assessed through quantal comparison in respect to their characteristics and parameters (Figure 2).

Figure 2 Evaluation of urban elements according to sustainable planting parameters

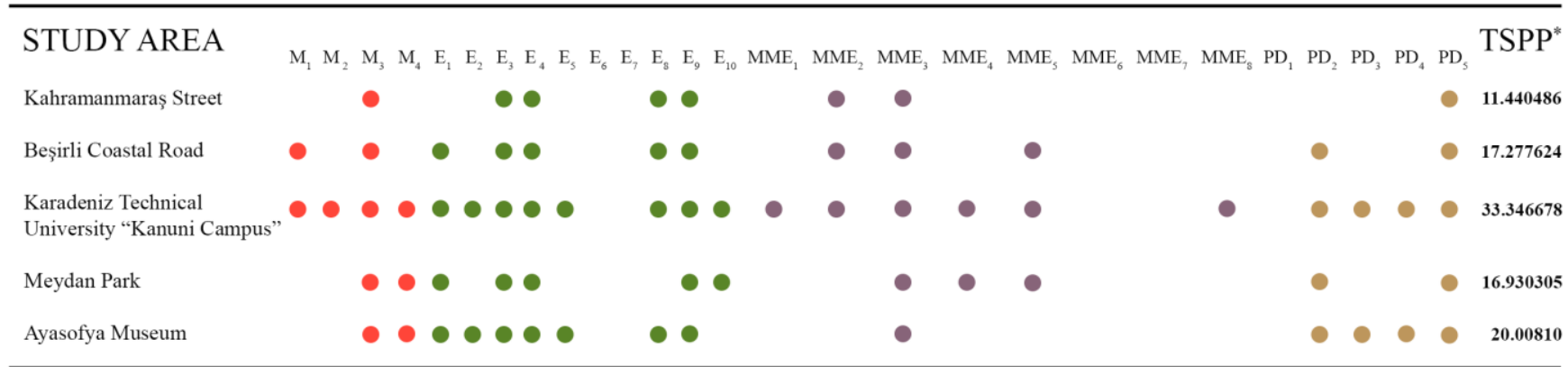

"Material" of Sustainable Planting Parameters / Sustainability Coefficients (SC): 2.0

"Ecology" of Sustainable Planting Parameters / Sustainability Coefficients (SC): 3.16

"Management / Maintenance / Economics" of Sustainable Planting Parameters / Sustainability Coefficients (SC): 2.55

"Planning / Design" of Sustainable Planting Parameters / Sustainability Coefficients (SC): 2.27

At the end of the assessments, it was seen that Maras Avenue scored highest in the "Ecology" main parameter among the 4 main parameters. Examination revealed that the avenue was rather insufficient in terms of sustainable planting parameters. Numerous problems (both botanic and structural) were spotted in Maras Avenue in terms of materials used. Sub-parameter of "Healthy specimens of plant species used in planting design and implementation" scored 0.666667 in the "Material" parameter. We detected that there was no endeavor relating water management of the plant species used and green spaces designed. It was also seen that most of the species used in the area were not domestic ones, rather they were species imported suitably for the climate. With the use of uniform species suitable for climate and soil characteristics, the area scored 6.337554 in the "Ecology" main parameter. In respect to "Management/Maintenance/Economy" main parameter, the area was considered only for spatial existence, no effort could be detected relating the management issues, which is indispensable for the sustainability of a given area. The area scored 3.276044 in "Management/Maintenance/Economy" main parameter and 1.160222 in "Planning/Design" main parameter. Based on these 
values, Total Sustainable Plantation Points (TSPP) of Maras Avenue is 11.440486 .

Besirli Coastal Road scored highest in the "Ecology" main parameter among the 4 main parameters (7.689332). Examinations indicated that recycled materials and endemic species were not preferred in the area. While the area scored 2.5 in the "Material" main parameter, it scored 4.515626 in "Management/Maintenance/Economy" and 2.572666 in "Planning/Design" main parameter. It was observed in the study area that no planning was made to support water harvest and recycling. Based on above-mentioned scores, TSPP of Beş irli Coastal Road is 17.277624.

Kanuni Campus of Karadeniz Technical University scored highest in the "Ecology" main parameter among the 4 main parameters. The investigations indicated that the campus is fairly sufficient in terms of sustainability parameters, yet endeavors on water management were far from being sufficient. On the other hand, it was observed that important steps were taken in using more and a wide variety of endemic species, as well as recycled materials. The area hosts all the sub-parameters listed under "Material" main parameter. While the area scored 5 in the "Material" main parameter, it scored 13.851332 in "Ecology" main parameter, 9.350014 in "Management/Maintenance/Economy" and 5.145332 in "Planning/Design” main parameter. Based on above-mentioned scores, TSPP of Kanuni Campus of Karadeniz Technical University is 33.346678 .

Meydan Park scored highest in the "Ecology" main parameter. Observations performed in the area revealed that the park came to a considerable extend in terms of sustainability parameters, but there were numerous deficiencies. Further deficiencies were spotted in the use of materials and in some other sub-parameters listed under "Management/Maintenance/Economy" main parameter. Besides, even if the arrangement of the area aimed at finding spatial solutions, ecological benefits of the materials used were not taken into consideration. While the area scored 1.86111 in the "Material" main parameter, it scored 8.777778 in "Ecology" main parameter, 3.7187517 in "Management/Maintenance/Economy" and 2.572665 in "Planning/Design" main parameter. Based on above-mentioned scores, TSPP of Meydan Park is 16.930305.

Lastly, Ayasofya Museum and its surroundings scored highest in the "Ecology" main parameter among the 4 main parameters. Examination revealed that the area was quite insufficient in terms of sustainable planting parameters. Especially, most of the insufficiencies derived from the "Management/Maintenance/Economy" main parameter. Further planning is needed for the area, which is used as a public space with its unique historical values, in terms of this parameter. While the area scored 1.86111 in the "Material" main parameter, it scored 11.779775 in "Ecology" main parameter, 1.221875 in "Management/Maintenance/Economy" and 5.145332 in "Planning/Design" main parameter. Based on above-mentioned scores, TSPP of Ayasofya Museum and its surroundings is 20.00810 .

\section{Conclusion And Recommendations}

As the result of the conducted study, it was revealed that the concept of sustainability cannot be limited to a single point of view, rather it has to be considered from multiple points of view in areas and designs where decision makers seek a decent level of sustainability. Planting design and implementations are among the primary tasks in open green spaces, which are included in the area of expertise of landscape architects. Therefore, the subject of 'planting' is especially important in considering open green spaces in terms of the concept of sustainability. Planting is not only about the species used in the given area. The notion also embraces the materials used in the planted sections of open green spaces, as well as the ecological qualities of the functions used and the contributions made to the nature and urban ecology. On the other hand, economy - which is always stressed in any work on sustainability- poses particular importance in sustainable planting schemes as well, because sustainability of projects which cost considerable amount of funds, requiring huge amounts of efforts and funds for maintenance due to lack of an intact management plan, usually come to a complete breakdown sooner or later. As it is known, design and planning are of utmost prominence in planting, as it is in any other project. The fact that all the decisions taken support the concept of sustainability and are shaped in accordance with this concept is particularly essential in planting efforts, where the subject matter is living beings.

In the scope of the current study, sustainable planting projects were scrutinized through urban elements, and an answer was sought for the question to what extend the existing planting projects in Trabzon are sustainable. To do that, certain parameters were specified with the help of literature, and urban elements were examined according to these parameters. Compared to others, Kanuni Campus of Karadeniz Technical University was found to have far higher Total Sustainable Plantation Points. Apart from ecological concepts, it is very important that the campus is administered in the scope of economic/management and preservation plans. However, the lack of an effort for water management is the main drawback of the campus area.

Maras Avenue, which is located in the heart of Trabzon, attained the lowest scores in terms of sustainable planting parameters. Examining the street works indicated that implementers did a negligent work with planting, and finished the work with only a few plant species scattered around the avenue. Despite the fact that the avenue hosts a dense traffic and it is surrounded by buildings, which is the main problem of the area, further efforts can be made to improve the ecological and environmental characteristics through better planting designs.

\section{References}

Acar, H., Gülpınar Sekban, D. Ü., \& Acar, C. (2017). Sustainable Design Approaches in Children's Playgrounds. In M. Özyavuz (Ed.), Sustainable Landscape Planning and Design 33-43. Frankfurt am Main: Peter Lang. 
Aklanoğlu, F. (2009). Geleneksel Yerleşmelerin Sürdürülebilirliği ve Ekolojik Tasarım: Konya-Sille Örneği. (Doktora Tezi), Ankara Üniversitesi, Ankara

Alberti, M. (1996). Measuring Urban Sustainability. Environmental Impact Assessment Review, 16: 381-424.

Alberti, M. (2005). The Effects of Urban Patterns on Ecosystem Function. International Regional Science Review, 28(2): 168-192. doi: $10.1177 / 0160017605275160$

ASLA. (2018). The Sustainable Sites Initiative.

Bozdoğan, B. (2003). Mimari Tasarım ve Ekoloji. (Yüksek Lisans), Yıldız Teknik Üniversitesi İstanbul.

Braulio-Gonzalo, M., Bovea, M. D., \& Ruá, M. J. (2015). Sustainability on the urban scale: Proposal of a structure of indicators for the Spanish context. Environmental impact assessment review, 53: 1630. doi:https://doi.org/10.1016/j.eiar.2015.03.002

Coccolo, S., Kämpf, J., Mauree, D., \& Scartezzini, J.-L. (2018). Cooling potential of greening in the urban environment, a step further towards practice. Sustainable Cities and Society, 38: 543-559. doi:https://doi.org/10.1016/j.scs.2018.01.019

Collins, A. (1999). Tourism Development and Natural Capital. Annals of Tourism Research, 26: 98-109.

Çakılcıoğlu, M. (2002). Sürdürülebilir Bir Kalkınma İçin; Sürdürülebilir Turizm. Paper presented at the 10. Ulusal Bölge Bilimi/Bölge Planlama Kongresi, 17-18 Ekim 2002., İstanbul.

Fitzgerald, J. (2010). Emerald Cities: Urban Sustainability and Economic Development. Oxford: Oxford University Press.

Gould, K. A., \& Lewis, T. L. (2017). Green Gentrification: Urban Sustainability and the Struggle for Environmental Justice. Oxon: Routledge.

Grimm, N. B., Faeth, S. H., Golubiewski, N. E., Redman, C. L., Wu, J., Bai, X., \& Briggs, J. M. (2008). Global Change and the Ecology of Cities. Science, 319(5864), 756.

Gülpınar Sekban, D. Ü., Bekar, M., \& Acar, C. (2018). Trabzon İlinin Yayla Turizmi Potansiyelinin Değerlendirilmesi ve Farkındalık iety, 40: 428-439. doi:https://doi.org/10.1016/j.scs.2018.04.002
Yönünden İncelenmesi. Uluslararası Bilimsel Araştırmalar Dergisi, 3(1):v349-361.

Hess, G. R., \& King, T. J. (2002). Planning Open Spaces For Wildlife: I. Selecting Focal Species Using A Delphi Survey Approach. Landscape and Urban Planning, 58(1): 25-40. doi:https://doi.org/10.1016/S0169-2046(01)00230-4

Lynch, K. (2010). Kent İmgesi, 1. İstanbul: Türkiye İş Bankası Kültür Yayınları.

Maclaren, W. H. (1996). Developing Indicators of Urban Sustainability: A Focus on the Canadian Experience. Toronto: ICURR Press.

Nikologianni, A., Moore, K., \& Larkham, P. J. (2019). Making Sustainable Regional Design Strategies Successful. Sustainability, 11(4): 1024.

Pickett, S. T. A., McGrath, B., Cadenasso, M. L., \& Felson, A. J. (2014). Ecological resilience and resilient cities. Building Research \& Information, 42(2): 143-157. doi:10.1080/09613218.2014.850600

Selman, P. (2008). What Do We Mean by Sustainable Landscape? Sustainability: Science, Practice and Policy, 4(2): 23-28. doi: $10.1080 / 15487733.2008 .11908019$

SKD. (2016). Rio +20 Zirvesi Ardından. Retrieved from http://www.skdturkiye.org/program/rio20zirvesiardindan-43 Date retrieved: April 22, 2020

Status of the World. (2016). Bir Kent Sürdürülebilir Olabilir Mi? . İstanbul: Ayhan Matbaası.

Stockholm Decleration. (1972). Report of the United Nations Conference on the Human Environment. Retrieved from Stockholm:

WCED. (1987). Our Common Future. Retrieved from http://www.un-documents.net/our-common-future.pdf Date retrieved: March 20, 2020

Xiao, X. D., Dong, L., Yan, H., Yang, N., \& Xiong, Y. (2018). The influence of the spatial characteristics of urban green space on the urban heat island effect in Suzhou Industrial Park. Sustainable Cities and Soc6 